This is the peer reviewed version of the following article: Journal of Food Science, Volume 82, Issue 9, Pages 2078-2084, which has been published in final form at https://doi.org/10.1111/1750-3841.13827 . This article may be used for non-commercial purposes in accordance with Wiley Terms and Conditions for Self-Archiving.

Desired Section: Food Chemistry

\title{
Optimization of Ripe Olive Processing with a Single Lye Treatment
}

Manuel Brenes, Concepción Romero and Pedro García-García

The Authors are with the Food Biotechnology Dept., Inst. de la Grasa (IG-CSIC), University Pablo de Olavide Campus, Building 46, Ctra. Utrera km 1, 41013 Seville, Spain. Direct inquiries to author García-García (E-mail: pedrog@cica.es).

Word count: 5039

Short version of title: Optimization of ripe olive processing 


\section{Cover letter}

Please find enclosed the manuscript with the title "Optimization of Ripe Olive Processing with a Single Lye Treatment" offered for publication in the "Journal of Food Science".

A previous publication (Effect of single alkali treatment on ripe olive characteristics, mainly the content in bioactive compounds) in the Journal of Food Science, 81, 2016, 26862691, showed the possibility of performing the oxidation of ripe olives with a single alkaline treatment instead of the traditional treatment with three lyes.

This paper studies how the new process is performed by reducing the volume of liquid to be used and therefore of wastewater.

It is proposed that the liquid in which the olives were previously preserved is used during the first washing step of darkening, therefore care must be taken regarding the concentration of acetic acid in this solution as a high content could cause adverse effects on color.

This causes a more intense black color to be achieved and it also contributes to the enrichment of the final product in bioactive substances such as phenolic compounds. 


\begin{abstract}
:
The development of a method for darkening black ripe olives during the washing step with a single $\mathrm{NaOH}$ treatment and preservation liquid was studied. Olives of the Hojiblanca cultivar were darkened at pilot plant scale, packed, sterilized, and analyzed after 2 months of storage at ambient temperature. It was found that the use of a mixture of preservation liquid:water at a ratio of 1:1 during the first washing gave rise to darker olives with slightly better firmness and no effect on sensory quality. However, care must be taken with the concentration of acetic acid in the preservation solution, as a content of this organic acid higher than $25 \mathrm{~g} / \mathrm{L}$ can cause adverse effects on olive color due to the low $\mathrm{pH}$ that can be reached in the flesh of the fruit. Additionally, the re-use of the preservation solution in the first washing resulted in enrichment in antioxidant compounds of the packed product. Black ripe olives processed with preservation liquid had a total phenolic content of $629 \mathrm{mg} / \mathrm{kg}$, whereas those with only tap water had 376 $\mathrm{mg} / \mathrm{kg}$, in particular hydroxytyrosol and hydroxytyrosol-4-glucoside. These findings mean that it is possible to get darker olives with higher contents in bioactive substances by re-using the preservation liquid during the darkening step of black ripe olives.
\end{abstract}

Keywords: darkening, oxidation, phenolic compounds, ripe olive, sodium hydroxide

Practical application: A new process for the production of black ripe olives has been developed by using a single lye treatment and preservation liquid during the darkening step. Processors will achieve a similar product to the traditional one obtained with a higher number of lyes and washing water. 


\section{Introduction}

Fruits producing ripe olives are usually harvested when they have a greenyellow color on their surface. Once in the canneries, olives are placed in buried fermenters under acidic conditions (De Castro and others 2007) in which they are kept until they are darkened. This phase consists of successive treatments (2-5) of the olives with dilute solutions of $\mathrm{NaOH}$, each followed by being washed with water for about 2024 hours. To neutralize excess alkali in the last wash, $\mathrm{CO}_{2}$ is bubbled in or food-grade hydrochloric acid is added (Sánchez-Gómez and others 2006). All this is done in horizontal cylindrical tanks in which air is injected through the bottom during the whole process. To avoid discoloration, the olives are placed in an iron solution (García and others 2001), and finally they are packed in closed containers that are sterilized to ensure proper preservation (Tang and others 2016). The final product has a low salt content, neutral pH, and a characteristic flavor (Sansone-Land and others 2014).

Olive darkening is caused by the oxidation of orthodiphenols, mainly hydroxytyrosol (3,4-dihydroxyphenyl ethanol) and caffeic acid, which polymerize to brown-black pigments (Brenes and others 1992), although a considerable amount of phenolic compounds (> $200 \mathrm{mg} / \mathrm{kg}$ ) can also be found in the packed product (Romero and others 2004; Melliou and others 2015), such as hydroxytyrosol, tyrosol, and hydroxytyrosol-4-glucoside, among others. These substances have been associated with numerous beneficial properties for health, such as antioxidant, anti-inflammatory, antimicrobial, and antitumor actions (Kountouri and others 2009; Medina and others 2009; Malheiro and others 2011; Martínez-Peláez and others 2013; Serreli and others 2017). Hence, the presence of phenolic compounds in black ripe olives is necessary for the formation of the black color, but they are also desirable in the final product due to their health benefits.

The current processing of black ripe olives is comprised of a large number of sodium hydroxide solutions (lye) and washings so that a high volume of wastewater is generated, and a great loss in phenolic compounds also occurs. Recently, it has been reported that ripe olives can be produced with a single lye treatment and 2 washings to achieve a final product with good color, flavor, and firmness, as well as a high content of bioactive substances such as phenolic compounds and triterpenic acids (Romero and others 2016a). Moreover, it was found that the re-use of the preservation liquid of olives 
intended for black ripe olives during the last washing step of the traditional process gives rise to darker and firmer olives (Brenes and others 1998). In addition, the presence of acid in these preservation liquids contributes to accelerating the neutralization of the olive flesh.

The objective of this study was to optimize the new single lye process by reusing the preservation liquid during the washing step in order to obtain firmer and darker olives, with a higher content in phenolic compounds.

\section{Materials and Methods}

\section{Olives and preservation liquids}

Fruits of the Hojiblanca cultivar (Olea europaea L.) stored for a period of 2 and 12 months in industrial tanks at the Agrosevilla SCA factory under acidic conditions were used for the assays (De Castro and others 2007). The olives were transported in their preservation liquids to the Instituto de la Grasa facilities.

\section{Oxidation chambers}

The oxidation process was carried out in 4 methacrylate horizontal cylindrical containers (20 cm Ø, $40 \mathrm{~cm}$ long). Two tubes $(5 \mathrm{~mm} \emptyset)$ were placed horizontally across the bottom of the cylinder where water circulates from a hot/cold thermostatic bath (Selecta, Spain) to maintain the desired temperature $\left(10\right.$ or $\left.30^{\circ} \mathrm{C}\right)$ during the washing stage. Air was bubbled $\left(0.2 \mathrm{~m}^{3} / \mathrm{h}\right)$ through the suspension along the horizontal bottom of the cylinder (20 diffusers). When desired, the $\mathrm{pH}$ of the liquid was controlled by a $\mathrm{pH}$ meter ( $\mathrm{pH} / \mathrm{mv}$ Controller 252, Crison, Spain) connected to an automatic dosage system which bubbled $\mathrm{CO}_{2}$ to neutralize the excess $\mathrm{NaOH}$ in the olive flesh.

\section{Design and development of experiments}

Assays were carried out on $2 \mathrm{~kg}$ of olives per chamber. Fruits were immersed in $2 \mathrm{~L}$ of a $\mathrm{NaOH}$ solution $(30 \mathrm{~g} / \mathrm{L})$ until it penetrated to the stone. Then the lye was 
removed and the olives were covered with either $2 \mathrm{~L}$ of tap water or another washing solution for $20 \mathrm{~h}$ (first washing). After draining, the fruits were put in a new washing solution (second washing) for 1 day and the $\mathrm{pH}$ of the liquid was maintained at $\mathrm{pH} 8.0$ units by adding $\mathrm{CO}_{2}$ to neutralize the excess $\mathrm{NaOH}$ in the olive flesh. To fix the black color formed, the fruits were immersed in a ferrous gluconate solution $(1 \mathrm{~g} / \mathrm{L})$ for another $24 \mathrm{~h}$. Air was bubbled in throughout the whole process.

Finally, $175 \mathrm{~g}$ of olives were bottled in A314 jars (Juvasa, Dos Hermanas, Spain) and covered with $145 \mathrm{~mL}$ of a solution containing $40 \mathrm{~g} / \mathrm{L} \mathrm{NaCl}$ and $0.2 \mathrm{~g} / \mathrm{L}$ ferrous gluconate. The jars were closed and sterilized in a computer-controlled Steriflow retort (Madinox, Barcelona, Spain) to reach a lethality value of $15 F_{0}$. The jars were kept at ambient temperature for 2 months, after which the superficial color, firmness, and phenolic compound content of the ripe olives were measured.

The different experiments carried out to optimize the darkening process are recorded in Figure 1 and explained below.

\section{Assay 1. Effect of performing one or two washings}

The darkening process was carried out with one single washing step for 48 hours or 2 washing cycles of $24 \mathrm{~h}$ each (control). The temperature in the washing water was maintained at $20{ }^{\circ} \mathrm{C}$. The olives used in this experiment had been previously preserved for 2 months at the olive factory. Experiments were run in duplicate.

\section{Assay 2. Use of preservation liquid during the first washing}

A mixture of preservation liquid and water (1:1) was used as the first washing solution during the darkening process. The effect of the temperature during the first and second washings $\left(10^{\circ} \mathrm{C}\right.$ or $\left.30^{\circ} \mathrm{C}\right)$ was also studied. The olives used in this experiment had been previously preserved for 12 months at the olive factory. Experiments were run in duplicate.

\section{Assay 3. Preservation liquid in the first or second washing water?}


The effect of the addition of preservation liquid during the first or second washing steps was studied. In both cases, the preservation liquid was added in a mixture 1:1 (preservation liquid:tap water). Experiments were carried out in duplicate with olives preserved for 12 months at the olive factory at $20^{\circ} \mathrm{C}$.

\section{Assay 4. Influence of acetic acid concentration in the preservation liquid}

Preservation liquid from olives stored for 2 months in the olive factory was used for the experiments. This liquid had a concentration of $7 \mathrm{~g} / \mathrm{L}$ acetic acid and was enriched with food-grade acetic acid up to $15 \mathrm{~g} / \mathrm{L}, 22 \mathrm{~g} / \mathrm{L}$ and $30 \mathrm{~g} / \mathrm{L}$. The four solutions $(7,15,22$, and $30 \mathrm{~g} / \mathrm{L}$ ) were diluted to 1:1 with tap water and they were used as the first washing waters during the darkening process. The experiments were run in duplicate at $10^{\circ} \mathrm{C}$.

\section{Physicochemical analyses}

The surface color of the fruits was expressed as reflectance at $700 \mathrm{~nm}\left(R_{700}\right)$ using a BYK-Gadner Model 9000 Color view spectrophotometer (Silver Spring, MD, USA). Lower reflectance values indicate darker fruit. Any interference from stray light was minimized by covering the samples with a box, which had a matted black interior. In addition, color was measured in terms of the CIE $L^{*} a^{*} b^{*}$ parameters. Results were the means of 10 determinations.

Firmness was measured using a Kramer shear compression cell coupled to an Instron Universal Testing Machine (Canton, MA, USA). The cross-head speed was 200 $\mathrm{mm} / \mathrm{min}$. The machine measures the shear compression force in Newtons $(\mathrm{N})$ and the firmness was expressed as N/100 g pitted olives. The value was the mean of 10 measurements, each of which was performed on three pitted olives.

The $\mathrm{pH}$ of the olives was measured by puncturing the flesh with a $\mathrm{pH}$ Spear instrument on 10 fruits (Eutech Instruments, Thermo Scientific).

The extraction of phenolic compounds from the olive pulp was based on the methodology proposed elsewhere (Ramírez and others 2014) using dimethyl sulfoxide (DMSO) and syringic acid as the internal standard. Prior to injection into the 
chromatograph, the mixture was filtered through a $0.22 \mu \mathrm{m}$ pore size nylon filter. The chromatographic system was: a Waters 717plus autosampler, a Waters 600E pump, a Waters heater module, and a Waters 996 diode array detector (Waters Inc., Milford, MA,

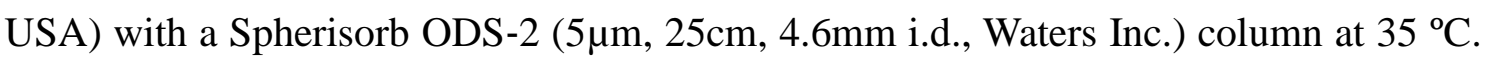
The separation of phenols was performed using a flow of $1 \mathrm{~mL} / \mathrm{min}$ of a gradient elution with an initial composition of $90 \%$ water ( $\mathrm{pH}$ adjusted to 2.7 with phosphoric acid) and $10 \%$ methanol, that was increased progressively. Phenolic compounds were monitored at $280 \mathrm{~nm}$.

\section{Sensory analysis}

The olives were tested according to the "Method for sensory analysis of table olives", COI/OT/MO 1/Rev.2 No 1 (IOC 2010) in the normalized testing room of the Instituto de la Grasa. The IOC method uses descriptors related to the perception of negative sensations to classify olives commercially, particularly for "abnormal flavor". Gustatory attributes (salty, bitter, and acidic) and kinesthetic sensations (hardness, fibrousness, crunchiness) were also assessed. The statistic used to indicate the values of the attributes was the mean of the individual data of the 8 testers and the variability by robust standard deviation. In addition, triangular tests were performed to compare the darkening of the olives according to the different methods assayed. Three samples (two the same and one different) were presented simultaneously to each taster, who was asked to distinguish the unpaired one. Each panelist performed 6 tests with the samples presented in all possible positions. Then, for comparison ( 8 tasters x 6 positions), 48 determinations were made.

\section{Statistical analyses}

Statistica software version 7.0 was used for data processing (Statistica for Windows, Tulsa, OK, USA). Comparison between mean variables was made by the Duncan's multiple range tests and the differences were considered significant when $p<$ 0.05 . 


\section{Results and Discussion}

\section{Effect of performing one or two washings}

As shown in Figure 2A, the color of the olives was the same after the first washing step $(19 \mathrm{~h}$ ) because all fruits were subjected to the same treatment. After $42 \mathrm{~h}$, the olives with only one single washing had a darker color (lower value of $R_{700}$ ) than those with 2 washing cycles, which could be tentatively attributed to the lower $\mathrm{pH}$ of the latter than the former (Figure 2B).

However, at the end of the color fixation step $(65 \mathrm{~h})$ the fruits with 2 washes presented a darker color than those with one single wash, despite the differences found in the $\mathrm{pH}$ of the olive flesh (Figure $2 \mathrm{~B}$ ). There is no explanation for this behavior, since Fe (II) binds to brown polymers formed from the oxidation of olive polyphenols such as hydroxytyrosol, and the intensity of this interaction is unknown (García and others 2001).

The neutralization of the olive pulp was faster when 2 washes were performed regardless of bubbling $\mathrm{CO}_{2}$ into the liquid of all treatments (Figure 2B). It must be taken into account that the diffusion of substances from the olives to the surrounding liquid and vice versa is influenced, to a large extent by the organic and mineral contents of the olives (Brenes and others 1993a), thereby a higher content of these substances in fruits treated with only one single wash could retard the diffusion phenomenon.

Differences in the color of the olives processed with one or 2 washes continued even after packing and a storage period of 2 months. The superficial color $\left(R_{700}\right)$ of the olives elaborated with one single washing maintained a higher reflectance value than those of 2 washings (Table 1). In addition, the texture of the latter olives was higher than the former, which was statistically significant $(p<0.05)$.

\section{Use of preservation liquid during the first washing}

The effect of the use of preservation liquid in the washing water at a ratio of 1:1 on the evolution of the color of olives with processing time is depicted in Figure 3. After the first washing step $(20 \mathrm{~h})$, the olives washed with preservation liquid at $10^{\circ} \mathrm{C}$ had a color similar to those processed at $30^{\circ} \mathrm{C}$ with tap water, and both olives showed a darker 
color than those processed without preservation liquid at $10^{\circ} \mathrm{C}$. It has been previously reported that an increase in temperature during washing favors development of the black color of olives (García and others 1991) as a consequence of $o$-diphenol oxidation (Brenes and others 1992). Although the effect of temperature on color decreased during the following washing and fixation steps, it was not as favorable as the effect caused by the use of preservation liquid.

It is important to emphasize the beneficial effect of the use of preservation liquid on the color as this liquid is enriched over time with phenolic compounds during the storage period of the fruit before the darkening process (Brenes and others 1993b), in particular hydroxytyrosol, an $o$-diphenol which is largely responsible for the formation of the black color (Brenes and others 1992). Therefore, the addition of these preservation liquids in the first wash involves the incorporation of a higher concentration of these substances into the process, which results in a more intense black color in the product.

Again, differences in the color of the olives before packing were maintained in the final product after 2 months of storage at ambient temperature (Table 1). Another quality parameter that was influenced by the use of preservation liquid during the first washing step was the firmness of the fruit. Packed olives processed with preservation liquid had a significantly higher texture after 2 months of storage than those processed with tap water at $10{ }^{\circ} \mathrm{C}$ or $30^{\circ} \mathrm{C}$. It must be noted that the re-use of fixing solutions in the packing process also produces an increase in the texture of olives (Romero and others 2016b).

\section{Preservation liquid in the first or second washing water?}

In the experiments discussed above, the beneficial effect on the color and texture of olives due to the use of preservation liquid during the first washing step has been shown. However, this liquid could also be added in the second washing instead of the first.

When the preservation liquid was added in the first washing, a slightly darker color (lower $R_{700}$ ) was observed in the olives after this step (Figure $4 \mathrm{~A}$ ). In addition, the reflectance decreased to a large extent after the second washing with only tap water in 
contrast to the use of preservation liquid in the second washing that caused a slight increase in reflectance at $700 \mathrm{~nm}$ in the olives. Differences in the color of both processed olives remained even after the color fixation step.

It is reasonable to relate the evolution of the color of olives during the darkening process with the $\mathrm{pH}$ of the olive flesh (Figure 4B), as the lower the $\mathrm{pH}$, the higher the reflectance of olives will be. After the first washing, the flesh $\mathrm{pH}$ was almost similar in the olives of the 2 treatments assayed (Figure 4B), which correlates with the similar color of the olives regardless of the treatment (Figure 4A). However, after the second washing, the $\mathrm{pH}$ of the olive flesh which had been processed with preservation liquid during this second washing step was much lower than those processed with preservation liquid during the first washing. Besides, differences in $\mathrm{pH}$ flesh between the olives of the 2 treatments were maintained until the end of the color fixation step with iron salt.

As was carried out in all the experiments, the darkened olives were finally packed, sterilized, and preserved for 2 months at ambient temperature. After this storage period, the fruits that had been processed with preservation liquid during the first washing had a $\mathrm{pH}$ in the flesh of 6.6, whereas those with the preservation liquid during the second washing had 6.0 units, which are very close values. The firmness of the olives was also similar regardless of the time of preservation liquid use (Table 1). By contrast, differences in olive color due to when the preservation liquid was added were also confirmed in these packed fruits, as those from the process with the preservation liquid in the first washing had lower $R_{700}$ values than those from the liquid in the second washing.

For all of the above, it seems that the addition of the preservation liquid should be done in the first washing as the olives can develop a darker color.

\section{Influence of acetic acid concentration in the preservation liquid}

Olives intended for processing as "black ripe" are currently preserved before the darkening step in a preservation liquid acidified with acetic acid, but the concentration of this organic acid varies among factories. 
The effect of the concentration of acetic acid in the preservation liquid added in the first washing on the evolution of the color of olives during darkening is depicted in Figure 5A. The higher the concentration of acetic acid, the higher the reflectance value reached in the olives during all the steps of darkening. It can be observed in Figure 5A that the color of olives after the fixation step with ferrous gluconate was rather similar for those processed with the preservation liquid containing $7 \mathrm{~g} / \mathrm{L}$ and $15 \mathrm{~g} / \mathrm{L}$ acetic acid. Furthermore, the increase in the content of acetic acid up to $22 \mathrm{~g} / \mathrm{L}$ in the liquid gave rise to discoloration of the olives, which was more intense when the content in acetic acid was $30 \mathrm{~g} / \mathrm{L}$. Again, a good correlation between the olive color reached (Figure 5A) and the evolution of the $\mathrm{pH}$ in the flesh during processing can be observed (Figure 5B).

The addition of preservation liquid to the washing water favored the darkening rate of olives, but it also contributed to accelerating the olive flesh neutralization. However, if the concentration of acetic acid in the preservation solution is higher than $22 \mathrm{~g} / \mathrm{L}$, a good dark color will not be reached in the final product because the $\mathrm{pH}$ of the flesh will be lower than 7-8 units. In fact, it can be observed in Figure 5B that the $\mathrm{pH}$ of the olives treated with the highest concentration of acetic acid in the preservation liquid $(30 \mathrm{~g} / \mathrm{L})$ decreased to a large extent during the first washing by nearly 6 units, therefore the addition of $\mathrm{CO}_{2}$ was not needed in this case during the following oxidation steps.

The firmness of packed olives after 2 months of storage at ambient temperature was statistically $(p<0.05)$ the same for all experiments (Table 1$)$ and the $\mathrm{pH}$ in the flesh ranged between 5.7 and 6.3 with a gradation according to the acid concentration used in the first washing. Likewise, the gradation in the black color of olives with decreasing concentration of acetic acid in the preservation liquid was maintained in the packed olives during storage for 2 months (Table 1).

\section{Effect of working conditions on sensory characteristics and content of phenolic compounds in the final product}

No mean value of the most frequently perceived defect of "negative sensations" ("abnormal flavor") exceeded the 3.0 value threshold (Table 2). Therefore, all black ripe olives from the experiments with and without preservation liquid during the darkening step were classified as "extra" commercial category, according to the IOC method. 
With regard to gustatory sensations (salty, bitter, and acidic) and kinaesthetic sensations (hardness, fibrousness, and crunchiness), the mean values were similar to commercial samples (García and others 2014), and they were statistically the same (p < $0.05)$ for the 2 experiments.

These results indicated that black ripe olives processed with preservation liquid during the washing step are marketable. However, a triangular test was carried out to compare differences between olives processed with and without the use of preservation liquid. The tasters identified the sample that was different from the other two in only 17 of the 48 tested, and according to Lawless and Heymann (2010), 24 correct answers are required to consider that the samples are different.

As previously mentioned, the production of ripe olives involves a first stage of fruit preservation during which the polyphenol compounds are diffused from the pulp into the aqueous medium. During this stage these substances, mainly oleuropein, undergo acid hydrolysis forming elenolic acid, glucose, and hydroxytyrosol as reaction products (Brenes and others 1993a). Also, in the darkening stage, treatments with sodium hydroxide chemically transform the remains of oleuropein and other phenolic compounds present in the fruits, such as verbascoside, releasing themselves under the presence of alkaline condition compounds such as hydroxytyrosol and caffeic acid (Brenes and others 1992). The successive washing steps and the oxidation conditions during darkening contribute to the low content of phenolic compounds detected in canned black ripe olives (Romero and others 2004; Melliou and others 2015).

Table 3 shows the concentration of phenolic compounds in packed black ripe olives that were processed using only tap water or a mixture of tap water and preservation liquid (1:1) during the first washing. It can be observed that the use of the latter solution gave rise to a significantly higher concentration of these bioactive substances in the final product, in particular hydroxytyrosol-4-glucoside and hydroxytyrosol. The content of total phenolic compounds was almost double in the olives processed with preservation liquid added during washing. Therefore, the use of preservation liquid during the darkening process not only favors the achievement of a good black color in the fruits, but also enriches the product with antioxidant phenolic compounds. 


\section{Conclusions}

The use of preservation liquid of olives intended for black ripe olives during their darkening step favors the achievement of the black color and it also contributes to the enrichment of the final product with bioactive substances such as phenolic compounds. It is recommended that this preservation liquid is used during the first washing step of darkening and care must be taken regarding the concentration of acetic acid in this preservation solution, as a high content could cause adverse effects on color. Overall, these findings open up the possibility of re-using the preservation liquid in the darkening step of olives processed with a single lye solution, as well as to make "healthier" black ripe olives.

\section{Acknowledgments}

This work was supported by the Spanish Government Project AGL-2013-42739$\mathrm{R}$ and the European Union FEDER funds. The authors thank Alejandra Expósito de la Cerda for her assistance with the experimental work.

\section{Authors' Contribution}

Manuel Brenes contributed to the design of the study, performed the experimental work, and interpreted the results. Concepción Romero designed the study, performed analyses, and contributed to interpretation of the results. Pedro García contributed to the design of the study, interpreted the results, and drafted the manuscript. 


\section{References}

Brenes M, García-García P, Garrido A. 1992. Phenolic compounds related to black color formed during the processing of ripe olives. J Agric Food Chem 40:1192-6.

Brenes M, García P, Romero C, Garrido A. 1993a. Study of the factors affecting the neutralization rate of olive flesh during the elaboration of black olives. Grasas y Aceites 44:190-4.

Brenes M, García P, Durán MC, Garrido A. 1993b. Concentration in phenolic compounds change in storage brines of ripe olives. J Food Sci 58:347-58.

Brenes M, García P, Romero C, Garrido A. 1998. Ripe olives storage liquids reuse during the oxidation process. J Food Sci 63:117-21.

De Castro A, García P, Romero C, Brenes M, Garrido A. 2007. Industrial implementation of black ripe olive storage under acid conditions. J Food Eng 80:1206-12.

García P, Brenes M, Garrido A. 1991. Effect of oxygen and temperature on the oxidation rate during the darkening step of ripe olive processing. J Food Eng $13: 259-71$

García P, Brenes M, Romero C, Garrido A. 2001. Colour fixation in ripe olives. Effects of type of iron salt and other processing factors. J Sci Food Agric 81:1364-70.

García P, Sánchez AH, Garrido A. 2014. Changes of physicochemical and sensory characteristics of packed ripe olives from Spanish cultivars during shelf-life. Int J Food Sci Technol 49:895-903.

IOC, International Olive Council. 2011. Method for the sensory analysis of table olives. http://www.internationaloliveoil.org/estaticos/view/224-testing-methods

Kountouri AM, Kaliora AC, Kounmbi L, Andrikopoulos NK. 2009. In-vitro gastric cancer prevention by a polyphenol-rich extract from olives through induction of apoptosis. Eur J Cancer Prev 18:33-9. 
Lawless H T, Heymann H. 2010.Sensory evaluation of food. Principles and practices. Springer: New York.

Malheiro R, Sousa A, Casal S, Bento A, Pereira JA. 2011. Cultivar effect on the phenolic composition and antioxidant potential of stoned table olives. Food Chem Toxicol 49:450-7.

Martínez-Peláez S, Covas M I, Fitó M, Kusàr A, Pravst I. 2013.Health effects of olive oil polyphenols: recent advances and possibilities for the use of health claims.Mol Nutr Food Res 57:760-71.

Medina E, Brenes M, García A, Romero C, De Castro A. 2009. Bactericidal activity of glutaraldehyde-like compounds from olive products. J Food Prot72:2611-4.

Melliou E, Zweigenbaum JA, Mitchell AE. 2015. Ultra-high pressure liquid chromatography triple-quadruple tandem mass spectrometry quantitation of polyphenols and secoiridoids in California-style black ripe olives and dry saltcured olives. J Agric Food Chem 63:2400-5.

Ramírez E, Medina E, Brenes M, Romero C. 2014. Endogenous enzymes involved in the transformation of oleuropein in Spanish table olive varieties. J Agric Food Chem62:9569-75.

Romero C, Brenes M, Yousfi K, García P, García A, Garrido A. 2004. Effect of cultivar and processing method on the contents of polyphenols in table olives. J Agric Food Chem 52:479-84.

Romero C, García-García P, Brenes M. 2016a. Enrichment of black olives in bioactive compounds using a single alkali treatment. J Food Sci 81:2686-91.

Romero C, García-Serrano P, García-García P, Brenes M. 2016b. Re-use of partially purified iron color fixation solutions using electro-coagulation and ozonation in ripe olive processing and packaging. J Food Eng 181:28-34.

Sánchez-Gómez AH, García-García P, Rejano-Navarro L. 2006. Elaboration of table olives. Grasas y Aceites 57:86-94. 
Sansone-Land A, Takeoka GR, Shoemaker CF. 2014. Volatile constituents of commercial imported and domestic black-ripe table olives (Olea europaea). Food Chem 149:285-95.

Serreli, G, Incani A, Atzeri A, Angioni A, Campus A, Cauli E, Zurru R, Deiana M. 2017. Antioxidant effect of natural table olives phenolic extract against oxidative stress and membrane damage in enterocyte-like cells. J Food Sci 82:380-5

Tang S, Avena-Bustillos R, Lear M, Sedej I, Holstege DM, Friedman M, McHugh TH, Wang S C. 2016. Evaluation of thermal processing variables for reducing acrylamide in canned black ripe olives. J Food Eng 191:124-30. 


\section{Figure legends}

Figure 1. Scheme of the assays carried out to optimize the darkening process of black ripe olives.

Figure 2. Influence of the number of washing steps on the superficial color (A) and the $\mathrm{pH}$ in the flesh (B) of the olives during darkening. Bars mean standard deviation of duplicates.

Figure 3. Influence of the temperature and the use of preservation liquid (diluted 1:1) in the first washing on the superficial color $\left(R_{700}\right)$ of olives during darkening. Bars mean standard deviation of duplicates.

Figure 4. Influence of the use of preservation liquid (diluted 1:1) in the first or second washing on the superficial color (A) and the $\mathrm{pH}$ in the flesh (B) of the olives during darkening. Bars mean standard deviation of duplicates.

Figure 5. Influence of different acetic acid concentrations in the preservation liquid used (diluted 1:1) in the first washing on the superficial color (A) and the flesh $\mathrm{pH}(\mathrm{B})$ of olives during darkening. Bars mean standard deviation of duplicates. 
Table 1

Table 1- Color and firmness of packed olives after 2 months of storage at ambient temperature.

\author{
Color $\left(\mathbf{R}_{700}\right)$ \\ Firmness (N/100 g pitted
}

olives)

Assay 1

One washing

$5.5(0.4) \mathrm{a}$

$1916(25) \mathrm{a}$

Two washings

$4.5(0.3) \mathrm{b}$

$2158(59) \mathrm{b}$

Assay 2

Water $10^{\circ} \mathrm{C}$

Water $30^{\circ} \mathrm{C}$

Preservation liquid $10^{\circ} \mathrm{C}$

Assay 3

Preservation liquid in

first washing

$5.0(0.8) \mathrm{a}$

2272 (95)a

Preservation liquid in

second washing

$$
7.1(0.1) b
$$

Assay 4

Acetic acid (7 g/L)

$5.8(0.2) \mathrm{a}$

$5.5(0.2) \mathrm{a}$

$6.6(0.1) b$

$7.3(0.2) \mathrm{c}$
Acetic acid $(15 \mathrm{~g} / \mathrm{L})$

Acetic acid (22 g/L)

Acetic acid (30 g/L)
$5.3(0.1) \mathrm{a}$

$2073(6) \mathrm{a}$

$1896(21) b$

$2312(119) \mathrm{c}$

Standard deviation of duplicates is shown in parentheses. Values in each column for the same experiment followed with the same letter are not significantly different at the 5\% level according to Duncan's multiple range test. 
Table 2

Table 2. Sensory evaluation of ripe olives elaborated using tap water or diluted preservation liquid in the first washing (1:1).

\begin{tabular}{cccccccc}
\hline & $\begin{array}{c}\text { Negative } \\
\text { sensations }\end{array}$ & \multicolumn{3}{c}{ Gustatory sensations } & & \multicolumn{2}{c}{ Kinaesthetic sensations } \\
\cline { 2 - 8 } & $\begin{array}{c}\text { Abnormal } \\
\text { Flavor }\end{array}$ & Salty & Bitter & Acid & Hardness & Fibrousness & Crunchiness \\
& $1.9(0.4) \mathrm{a} a$ & $3.6(0.9) \mathrm{a}$ & $2.3(0.6) \mathrm{a}$ & $1.9(0.2) \mathrm{a}$ & $3.6(0.1) \mathrm{a}$ & $4.7(0.8) \mathrm{a}$ & $2.1(0.4) \mathrm{a}$ \\
\hline Preservation liquid/tap water & $1.5(0.3) \mathrm{a}$ & $3.4(0.2) \mathrm{a}$ & $1.7(0.3) \mathrm{a}$ & $1.9(0.1) \mathrm{a}$ & $3.2(0.3) \mathrm{a}$ & $4.4(0.5) \mathrm{a}$ & $2.1(0.1) \mathrm{a}$
\end{tabular}

${ }^{\mathrm{a}}$ Robust standard deviation in parentheses; ${ }^{\mathrm{b}}$ Means in each column followed by different letters are significantly different $(p<0.05)$. 
Table 3

Table 3- Influence of the use of preservation liquid during the first washing step of the darkening process on the phenolic compound concentration $(\mathrm{mg} / \mathrm{kg})$ in canned black ripe olives.

\begin{tabular}{lcc}
\hline Phenolic compound & Tap water during washing & $\begin{array}{c}\text { Preservation liquid: tap } \\
\text { water (1:1) }\end{array}$ \\
\hline Hydroxytyrosol-4-glucoside & $215(1)^{\mathrm{a}} \mathrm{a}^{\mathrm{b}}$ & $373(52) \mathrm{b}$ \\
Hydroxytyrosol & $70(2) \mathrm{a}$ & $138(37) \mathrm{b}$ \\
Tyrosol & $31(2) \mathrm{a}$ & $43(7) \mathrm{a}$ \\
Salidroside & $36(6) \mathrm{a}$ & $56(2) \mathrm{b}$ \\
Others & & $20(2) \mathrm{b}$ \\
Total & $25(2) \mathrm{a}$ & $629(41) \mathrm{b}$
\end{tabular}

\footnotetext{
${ }^{a}$ Average value of duplicates and standard deviation are shown in parentheses. ${ }^{b}$ Row values followed by the same letter do not differ at the 5\% level of significance according to Duncan's multiple range test. 'Sum of $p$-coumaric acid, hydroxytyrosol acetate, luteolin, and rutin concentrations.
} 


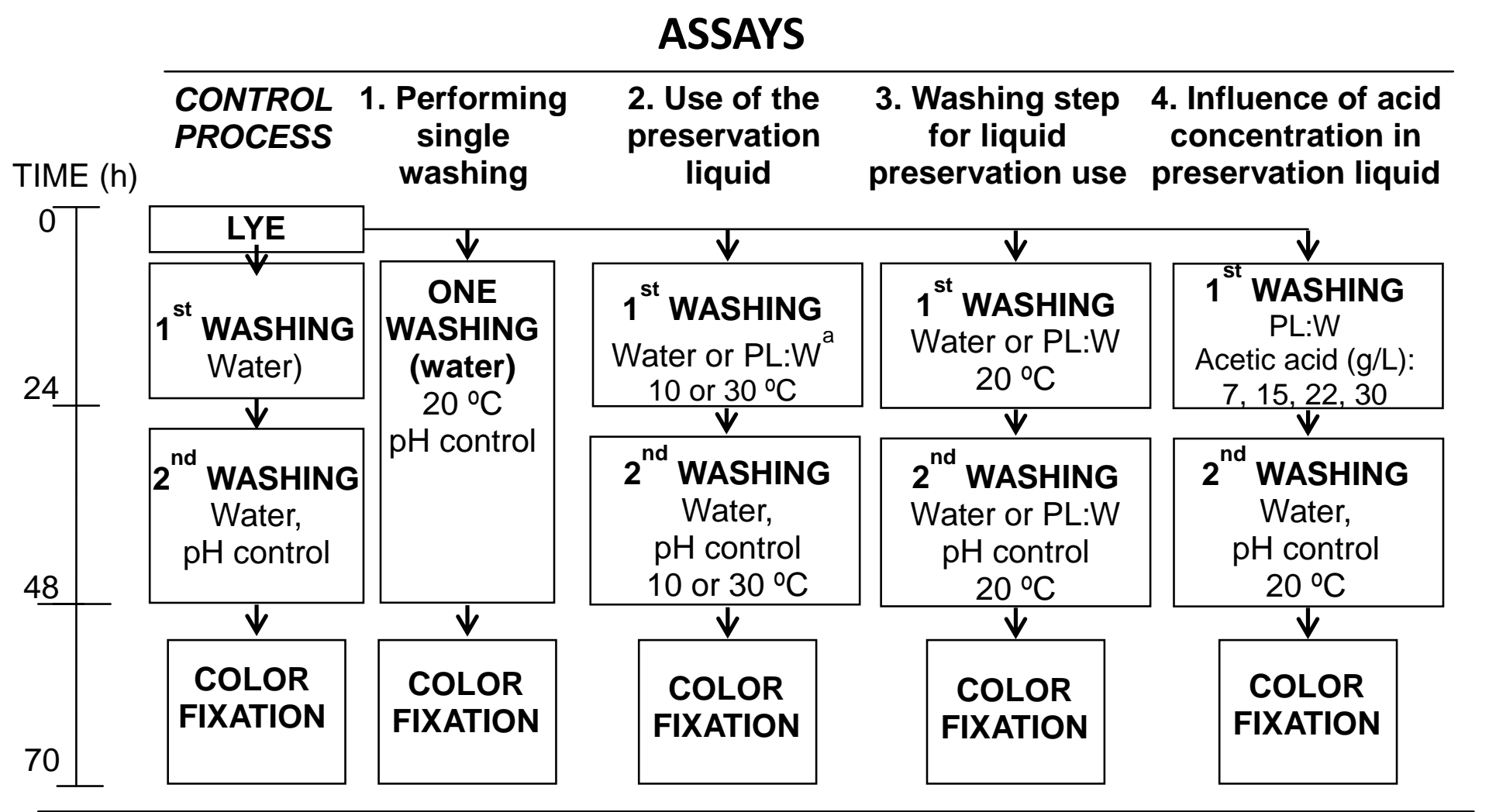

Note: ${ }^{a}$ (PL:W) Preservation liquid:Water (1:1) as washing liquid 
Figure 2
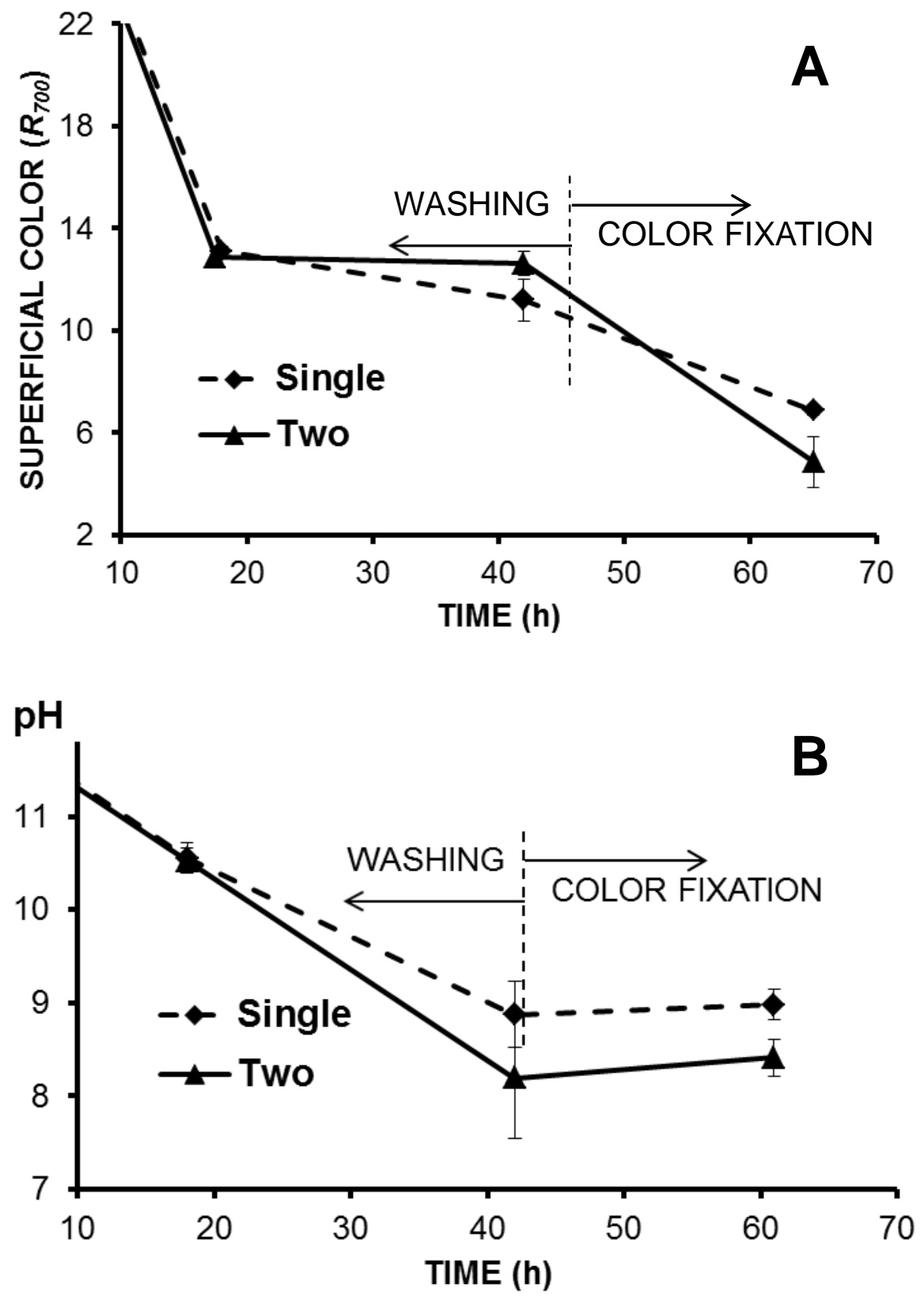

Figure 2 
Figure 3

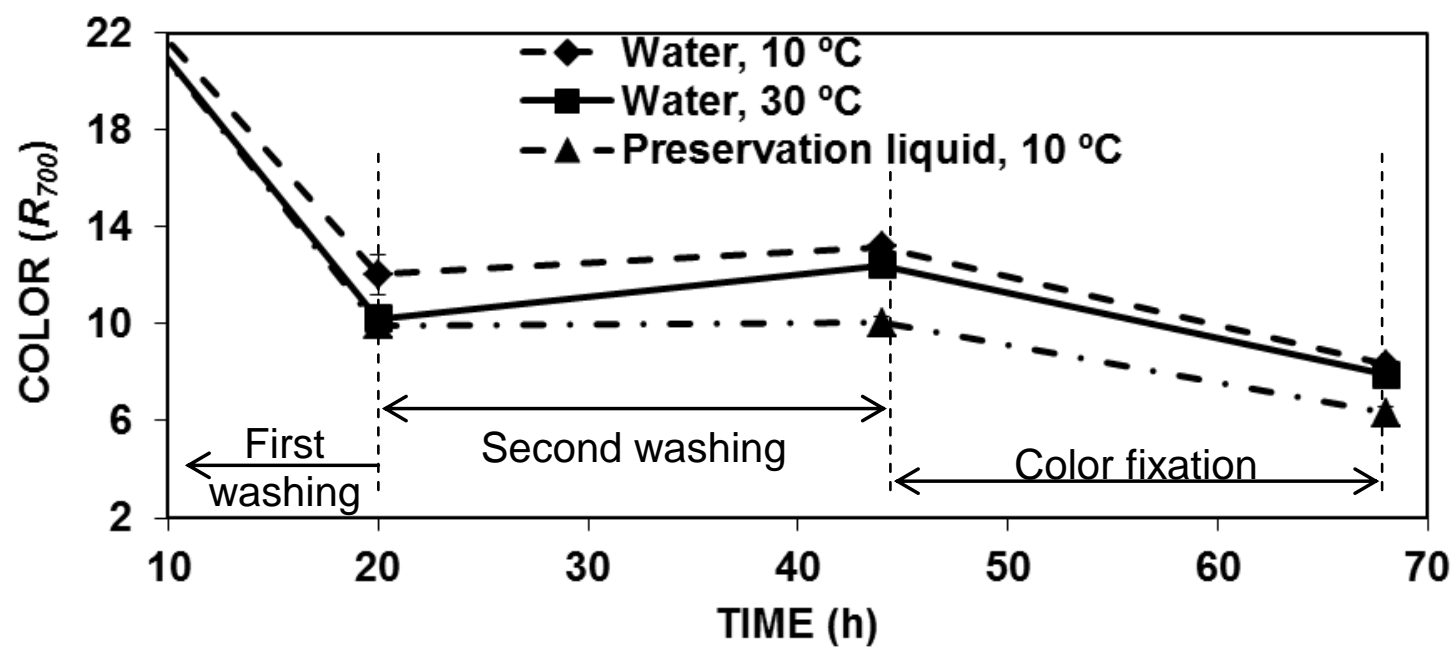

Figure 3 
Figure 4
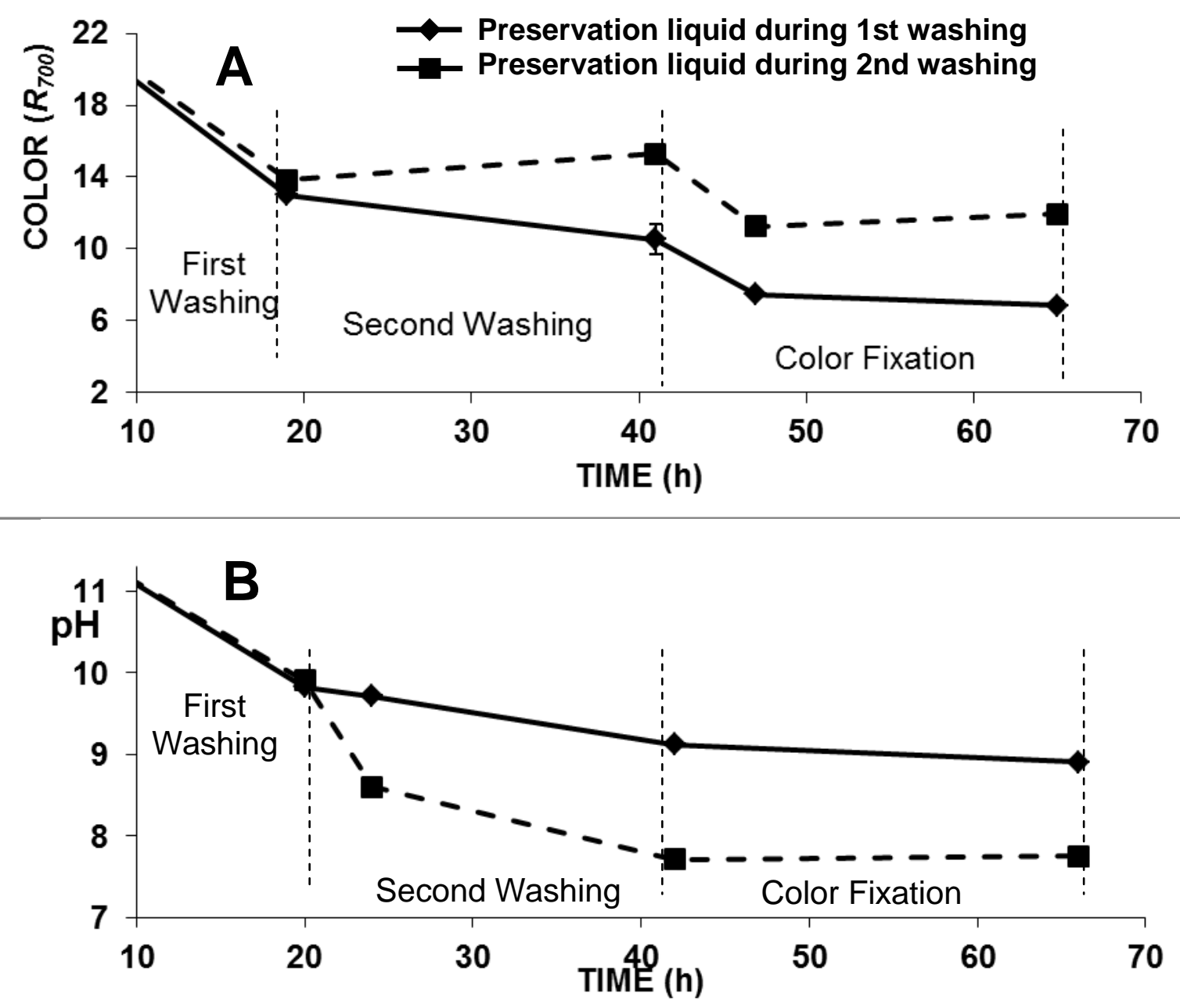

Figure 4 
Figure 5
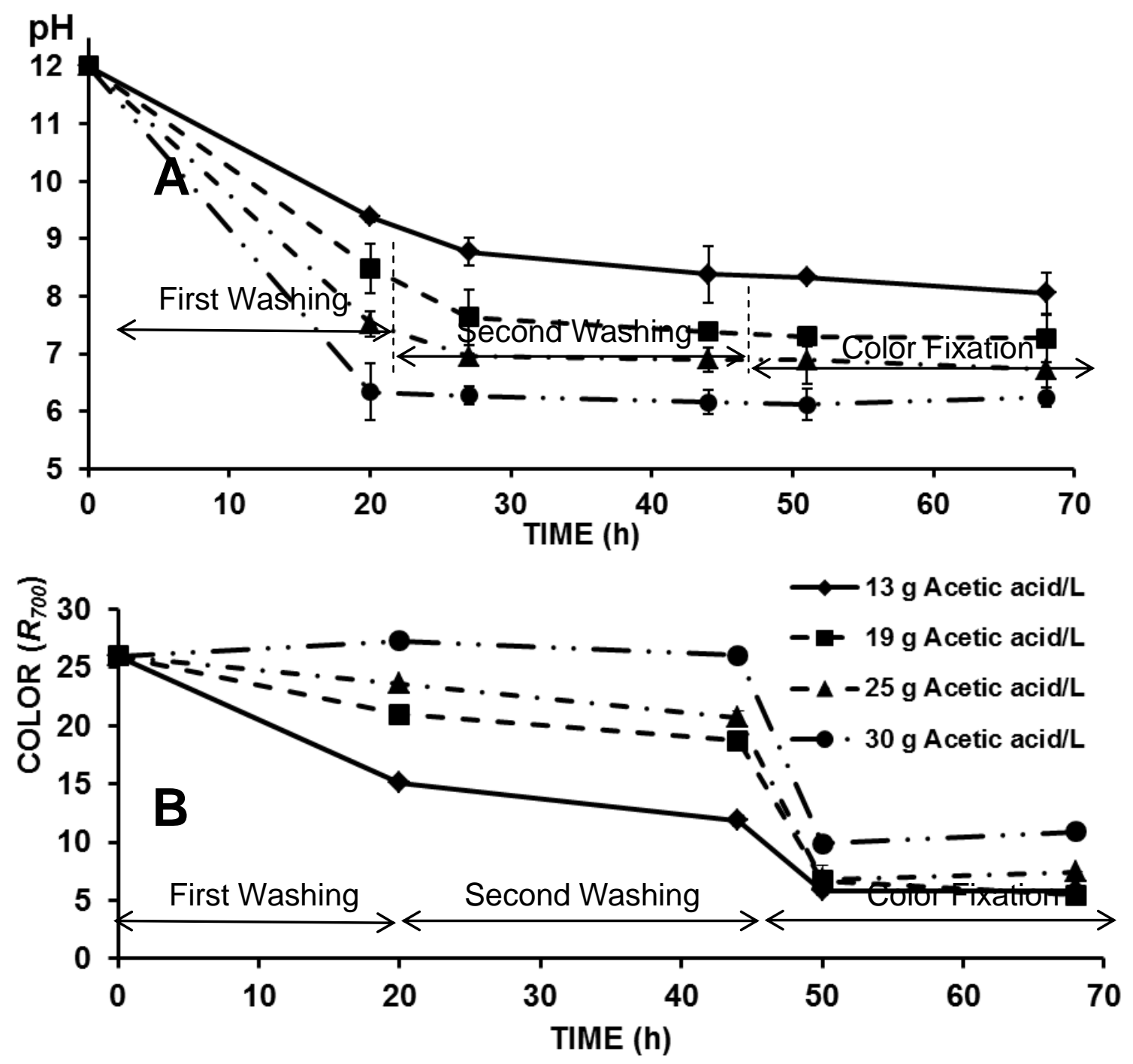

Figure 5 